\title{
Identificação de raças fisiológicas de Magnaporthe grisea em áreas de arroz irrigado no Estado do Tocantins
}

\author{
Liamar M. Anjos, Gil R. Santos, Justino J. Dias Neto, Wilson F. Oliveira \& Manoel D. Castro Neto \\ Departamento de Fitopatologia, Universidade Federal do Tocantins, 77.402-970, Gurupi, TO, Brasil
}

Autor para correspondência: Gil R. Santos, e-mail: gilrsan@uft.edu.br

\section{RESUMO}

A brusone, causada pelo fungo Magnaporthe grisea, é a doença mais importante da cultura do arroz no Brasil, constituindo fator limitante para a produtividade. Este trabalho teve por objetivo identificar raças de $M$. grisea, predominantes no estado do Tocantins buscando-se estudar a variabilidade do patógeno na região para possibilitar o desenvolvimento e recomendação de cultivares de arroz resistentes à brusone. Para a obtenção de isolados do patógeno foram feitas coletas em plantas doentes nas áreas experimentais constituídas de três ensaios de multilinhas e cultivares compostas de arroz irrigado localizados em dois municípios representativos do Estado do Tocantins. Foi obtido um total de 250 isolados monospóricos que em seguida foram inoculados em uma Série Internacional de Diferenciadoras (SID). Foi identificado um total de 45 raças, sendo que a raça que ocorreu com maior prevalência foi a IA-1 em $24,8 \%$ dos isolados, seguida pela IA-65 em 11,2\% e IA-33 em 6,4\%. Maior número de raças foi encontrado nos ensaios localizados no município da Lagoa da Confusão, seguido de Formoso do Araguaia, no Projeto Formoso e na área da Unitins-Agro. Na população do fungo M. grisea amostrada, encontrou-se uma grande variabilidade, com prevalência das raças dos grupos IA, IB e ID.

Palavras-chave: Oryza sativa, Pyricularia grisea, brusone.

\begin{abstract}
Identification of physiological races of Magnaporthe grisea in areas of rice irrigated in the State of Tocantins

In Brazil, the most important disease in rice is blast, which is caused by the fungus Magnaporthe grisea. This disease is considered to be a limiting factor for rice productivity. This work aimed to determine the prevalent races of the rice blast pathogen $M$. grisea in the state of Tocantins, in order to study the variability in the region and make it possible to develop and recommend blast-resistant rice cultivars. To assess this information, infected leaves were collected from three experimental sites, each consisting of multilines and a varietal mixture of irrigated rice in Tocantins state. A total of 250 monosporic isolates were obtained. Subsequently, these isolates were inoculated in the International Standard Differential (ISD). A total of 45 races were identified, where the most prevalent race was IA$1(24.8 \%$ of the isolates), followed by IA-65 (11.2\%) and IA-33 (6.4\%), respectively. The highest number of races was found in the experimental site located at Lagoa da Confusão, followed by Formoso do Araguaia (Projeto Formoso) and Unitins-Agro, respectively. In the population of $M$. grisea under study, a high variability was found with prevalence of the race groups: IA, IB and ID.
\end{abstract}

Keywords: Oryza sativa, Pyricularia grisea, rice blast.

A brusone causada pelo fungo Magnaporthe grisea (T.T. Hebert) M.E. Barr (anamorfo Pyricularia grisea Sacc.) é a doença mais importante da cultura do arroz (Oryza sativa L.) no Brasil e no Mundo devido aos prejuízos que provoca na produtividade e na qualidade dos grãos. O desenvolvimento de cultivares resistentes é o método mais viável de controle dessa doença. Entretanto, no estado do Tocantins, cultivares melhoradas e com resistência moderada têm se tornado inefetivas em apenas dois a três anos após o seu lançamento devido à alta variabilidade apresentada pelo patógeno (Rangel et al., 2006; Prabhu \& Filippi, 2006; Santos et al., 2003). Após alguns anos de

Parte da Dissertação de Mestrado da primeira autora. Universidade Federal do Tocantins. Gurupi TO. 2008. plantio de uma mesma cultivar, a elevada pressão de seleção sobre o patógeno pode superar a resistência por causa do surgimento ou aumento da freqüência de uma nova raça fisiológica, virulenta à cultivar anteriormente resistente (Prabhu et al., 2002b).

A maioria dos estudos conduzidos no Brasil e em outros países concentrou-se na determinação e composição de raças, na sua freqüência de ocorrência e na sua compatibilidade com genes de resistência conhecidos. A diversidade patogênica é geralmente alta em campos experimentais e nos locais de testes de seleção para melhoramento de cultivares (Filippi et al., 1999). Segundo Bedendo et al. (1979), podem ocorrer diferentes raças fisiológicas em uma lesão produzida pelo fungo em planta de arroz. Em outros Estados brasileiros, estudos para identificar raças de $M$. grisea também foram realizados (Cornelio et al., 2003; Filippi et al., 1999; Silva et al.,2009). O presente 
trabalho teve como objetivo identificar as raças fisiológicas de $M$. grisea prevalentes no estado do Tocantins, buscandose estudar a variabilidade do patógeno na região de modo que se possa contribuir com os programas de melhoramento para resistência possibilitando o desenvolvimento e recomendação de cultivares de arroz resistentes à brusone.

As coletas foram feitas em ensaios multilinhas (famílias RC3) desenvolvidas pela EMBRAPA. Os ensaios foram constituído por 11 tratamentos, sendo três multilinhas (CNA8502, Diamante e Formoso), quatro cultivares compostas (Formoso + Diamante, Formoso + CNA8502, Diamante + CNA8502 e Formoso + Diamante + CNA8502) e quatro cultivares testemunhas (CNA8502, Diamante, Epagri 109 e Formoso). Os experimentos foram instalados em dois municípios produtores de arroz irrigado do Estado do Tocantins, Lagoa da Confusão e Formoso do Araguaia (Projeto Formoso e Unitins-Agro), no ano agrícola de 2007/2008, no delineamento experimental de blocos completos ao acaso com três repetições. Cada parcela foi representada por cinqüenta linhas de 50 metros de comprimentos e com espaçamento de 0,20 metros entre linhas. A densidade de semeadura foi de 100 sementes por metro linear. A adubação de plantio (430 $\mathrm{kg} \cdot \mathrm{ha}^{-1}$ da fórmula 05-25-15) foi feita no próprio sulco, e, aos 55 dias após o plantio (DAP), realizou-se cobertura com uréia $\left(100 \mathrm{~kg} \mathrm{ha}^{-1}\right)$. Foram realizadas seis coletas durante todo o ciclo da cultura, sendo quatro na fase vegetativa e duas na fase reprodutiva para panícula.

Foram testados 250 isolados monospóricos que foram classificados em 45 Raças (Tabela 2). Os isolados monospóricos, obtidos a partir de folhas e panículas com lesões esporulativas de brusone. Entre 10 e 14 dias de crescimento em meio de cultura de BDA em placas de petri, o micélio superficial do isolado foi removido com alça de platina, e as placas colocadas sob luz fluorescente contínua por 48 horas para estimular a conidiogênese. A solução de inóculo foi preparada através da remoção dos conídios com água estéril e o auxílio de um pincel. A suspensão conidial foi ajustada para a concentração de $3 \times 10^{5}$ conídios $\mathrm{mL}^{-1}$.

Para a identificação das raças fisiológicas utilizou-se a Série Internacional de Diferenciadoras (SID), conforme Ling \& Ou, (1969). As diferenciadoras foram semeadas em bandejas plásticas, utilizando 12 sementes por sulco e mantidas em casa de vegetação climatizada. As plantas foram inoculadas aos 25 dias após a emergência, utilizandose um pulverizador manual e mantidas em câmara úmida com ausência total de luz por 24 horas, a uma temperatura média de $25^{\circ} \mathrm{C}$ e umidade relativa acima de $95 \%$, para manter o molhamento ou orvalho nas folhas durante o processo de germinação e infecção do patógeno. As avaliações foram realizadas aos sete dias após a inoculação, utilizando-se uma escala de notas de 0 a 9 (Leung et al., 1988). A reação da planta foi considerada resistente quando recebeu notas de severidade menor ou igual a 3 e suscetível quando a nota foi igual ou superior a 4. Cada diferenciadora foi considerada suscetível ao apresentar mais de 30\% das plantas com lesões em cada inoculação.
As dez raças predominantes foram, em ordem decrescente de frequência: IA-1, IA-65, IA-33, IC-1, IA-9, IA-109, ID-1, ID-9, IA-41 e IA-97 que, juntas corresponderam a $70,8 \%$ do total de 250 isolados. Além destas, foram identificadas também outras 35 raças, porém com menor freqüência (Tabela 1). A maior diversidade de raças foi encontrada na população de $M$. grisea amostrada em Lagoa da Confusão, seguida da população amostrada no Projeto Formoso e em UNITINS-Agro, com uma predominância da raça IA-1 nos três locais amostrados e uma freqüência de $24,8 \%$ do total de isolados avaliados (Tabela 2). Esta raça foi, também, a mais freqüente nos resultados obtidos em Minas Gerais por Cornélio et al. (2003), encontrada em quatro das cinco cultivares estudadas com $18,4 \%$.

Entre os municípios do Tocantins, o maior produtor é Lagoa da Confusão com 29.200 ha, seguida de Formoso do Araguaia com 12.200 ha (SEAGRO-TO, 2008). Apesar de a amostragem ter sido realizada em um ensaio composto pelos mesmos tratamentos nos três locais amostrados, é possível considerar que a amostragem realizada seja representativa da diversidade do patógeno presente em lavouras das regiões amostradas. No ensaio de Lagoa da

TABELA 1 - Grupos mostrando as raças de $M$. grisea identificadas nos três ensaios de arroz irrigado constituídos de multilinhas e cultivares compostas no Estado do Tocantins, na safra 2007/2008

\begin{tabular}{|c|c|c|c|c|c|c|c|c|}
\hline \multicolumn{9}{|c|}{ Grupos da SID ( I ) } \\
\hline $\mathbf{A}$ & B & $\mathbf{C}$ & D & $\mathbf{E}$ & $\mathbf{F}$ & G & $\mathbf{H}$ & I \\
\hline IA-1 & IB-1 & IC-1 & ID-1 & IE-1 & IF-1 & IG-1 & - & - \\
\hline IA-3 & IB-3 & IC-9 & ID-3 & IE-3 & - & - & - & - \\
\hline IA-9 & IB-5 & IC-13 & ID-5 & - & - & - & - & - \\
\hline IA-10 & IB-9 & IC-17 & ID-7 & - & - & - & - & - \\
\hline IA-13 & IB-17 & - & ID-9 & - & - & - & - & - \\
\hline IA-33 & IB-21 & - & ID-15 & - & - & - & - & - \\
\hline IA-34 & IB-26 & - & - & - & - & - & - & - \\
\hline IA-35 & IB-33 & - & - & - & - & - & - & - \\
\hline IA-37 & IB-41 & - & - & - & - & - & - & - \\
\hline IA-41 & IB-57 & - & - & - & - & - & - & - \\
\hline IA-45 & IB-58 & - & - & - & - & - & - & - \\
\hline IA -57 & - & - & - & - & - & - & - & - \\
\hline IA-65 & - & - & - & - & - & - & - & - \\
\hline IA-73 & - & - & - & - & - & - & - & - \\
\hline IA-77 & - & - & - & - & - & - & - & - \\
\hline IA-97 & - & - & - & - & - & - & - & - \\
\hline IA-101 & - & - & - & - & - & - & - & - \\
\hline IA-105 & - & - & - & - & - & - & - & - \\
\hline IA-109 & - & - & - & - & - & - & - & - \\
\hline IA-121 & - & - & - & - & - & - & - & - \\
\hline 20 (128) & $11(64)$ & $4(32)$ & $6(16)$ & $2(8)$ & $1(4)$ & $1(2)$ & 0 (1) & 0 (1) \\
\hline
\end{tabular}


Confusão, na população composta por 95 isolados, foram identificadas 27 raças, com $25,3 \%$ dos isolados pertencentes ao patótipo IA-1. No Projeto Formoso, foi identificado um total de 26 raças, sendo mais prevalente a raças IA-65, correspondendo a $17,6 \%$ dos 85 isolados. No experimento da Unitins-agro, uma região mais isolada, com menor área cultivada (4.000 ha) e menor número de cultivares plantadas, foram identificadas apenas 18 raças, sendo que a raça IA-1 foi representada por 28 isolados, correspondendo a $70 \%$ do total amostrado. Por outro lado, várias raças menos frequentes só foram encontradas em um dos ensaios (Tabela 2).

Comparando-se esses resultados com os obtidos por outros pesquisadores, destaca-se a raça IB-9, que tem sido relatada em outros trabalhos como uma das mais freqüentes (Cornelio et al., 2003; Prabhu et al., 2002a; Filippi et al., 1999; Filippi \& Prabhu, 2001), e que no presente trabalho foi identificada em apenas um isolado. Em outro estudo, realizado por Prabhu et al. (2002b), com coletas em nove lavouras comerciais nos municípios de Lagoa da Confusão e Dueré, nas cultivares de arroz irrigado Epagri 108 e
109, o patótipo IB-45 apesar de ter ocorrido em $83 \%$ dos isolados, não foi detectado no presente trabalho. $\mathrm{O}$ fato de tais cultivares serem pouco cultivadas atualmente pode ter contribuído para a sua baixa freqüência ou sua ausência nos locais amostrados.

Os resultados obtidos no Estado do Tocantins mostraram que existe nas regiões produtoras de arroz irrigado uma grande diversidade de raças de $M$. grisea. Tal fato é indicativo de que nas regiões produtoras de arroz irrigado no estado do Tocantins, há uma grande diversidade de raças de $M$. grisea, o que pode explicar a rápida "quebra" de resistência das cultivares a qual tem ocorrido entre 2 e 3 anos após o seu lançamento (Rangel et al., 2006; Santos et al., 2003; Prabhu \& Filippi, 2006). Em outras regiões do Brasil tem sido verificado de modo geral, um menor número de raças. Em Minas Gerais, Cornelio et al. (2003), identificaram 14 raças em 138 isolados monospóricos, provenientes de 23 amostras, onde as raças IA-9, IA-1, IB-9 e IC-9 ocorreram com maior freqüência. As raças identificadas nos três locais amostrados distribuíram-se em sete dos nove grupos de raças possíveis para identificação através das diferenciadoras

TABELA 2 - Raças fisiológicas de $M$. grisea identificadas em áreas experimentais de arroz irrigado instaladas em três locais: Lagoa da Confusão (LC), Formoso do Araguaia no Projeto Formoso (PF) e na Unitins-Agro (UA), no ano agrícola de 2007/2008

\begin{tabular}{llcccccccccccc}
\hline \hline Raças & LC & PF & UA & Total & \% & & Raças & LC & PF & UA & Total & \% \\
\hline 1 & IA-1 & 24 & 10 & 28 & 62 & 24,8 & 24 & IA-10 & - & - & 1 & 1 & 0,4 \\
2 & IA-65 & 6 & 15 & 7 & 28 & 11,2 & 25 & IA-34 & - & 1 & - & 1 & 0,4 \\
3 & IA-33 & 6 & 8 & 2 & 16 & 6,4 & 26 & IA-35 & 1 & - & - & 1 & 0,4 \\
4 & IC-1 & 6 & - & 8 & 14 & 5,6 & 27 & IA-37 & 1 & - & - & 1 & 0,4 \\
5 & IA-9 & 3 & 4 & 5 & 12 & 4,8 & 28 & IA-45 & - & 1 & - & 1 & 0,4 \\
6 & IA-109 & 4 & 6 & - & 10 & 4,0 & 29 & IA-57 & - & 1 & - & 1 & 0,4 \\
7 & ID-1 & 2 & 6 & 2 & 10 & 4,0 & 30 & IA-101 & 1 & - & - & 1 & 0,4 \\
8 & ID-9 & 7 & 2 & - & 9 & 3,6 & 31 & IA-121 & - & 1 & - & 1 & 0,4 \\
9 & IA-41 & 2 & 4 & 2 & 8 & 3,2 & 32 & IB-3 & 1 & - & - & 1 & 0,4 \\
10 & IA-97 & 2 & 5 & 1 & 8 & 3,2 & 33 & IB-5 & - & 1 & - & 1 & 0,4 \\
11 & IB-1 & 6 & 1 & - & 7 & 2,8 & 34 & IB-9 & - & 1 & - & 1 & 0,4 \\
12 & IA-73 & 3 & 2 & 1 & 6 & 2,4 & 35 & IB-17 & - & 1 & - & 1 & 0,4 \\
13 & IB-41 & - & 4 & 2 & 6 & 2,4 & 36 & IB-21 & 1 & - & - & 1 & 0,4 \\
14 & IE-1 & 2 & 4 & - & 6 & 2,4 & 37 & IB-26 & 1 & - & - & 1 & 0,4 \\
15 & IA-13 & 2 & - & 2 & 4 & 1,6 & 38 & IB-57 & - & 1 & - & 1 & 0,4 \\
16 & IA-105 & 3 & - & 1 & 4 & 1,6 & 39 & IB-58 & - & - & 1 & 1 & 0,4 \\
17 & IF-1 & 4 & - & - & 4 & 1,6 & 40 & IC-17 & 1 & - & - & 1 & 0,4 \\
18 & IB-33 & 1 & 1 & 1 & 3 & 1,2 & 41 & ID-3 & - & - & 1 & 1 & 0,4 \\
19 & IA-77 & - & - & 3 & 3 & 1,2 & 42 & ID-5 & - & 1 & - & 1 & 0,4 \\
20 & IA-3 & - & - & 2 & 2 & 0,8 & 43 & ID-7 & - & 1 & - & 1 & 0,4 \\
21 & IC-9 & - & 2 & - & 2 & 0,8 & 44 & IE-3 & - & 1 & - & 1 & 0,4 \\
22 & IC-13 & 2 & - & - & 2 & 0,8 & 45 & IG-1 & 1 & - & - & 1 & 0,4 \\
23 & ID 15 & 2 & & & 2 & 0,8 & & & & & & \\
\hline Total de raças identificadas & & & & & $\mathbf{2 7}$ & $\mathbf{2 6}$ & $\mathbf{1 8}$ & & \\
\hline Total de Isolados Monospóricos & & & & $\mathbf{9 5}$ & $\mathbf{8 5}$ & $\mathbf{7 0}$ & $\mathbf{2 5 0}$ & \\
\hline
\end{tabular}


internacionais (Atkins et al., 1967) e conforme chave de identificação proposta por Ling \& Ou (1969). Filippi et al. (1999), estudando a compatibilidade diferencial de isolados de $M$. grisea em algumas cultivares de arroz irrigadas, identificaram sete raças entre os 24 isolados testados, sendo predominante a raça IB-9, que foi detectada em oito das onze cultivares. Filippi \& Prabhu (2001), estudando a virulência fenotípica de $M$. grisea, identificaram 16 raças fisiológicas provenientes de 71 isolados monospóricos, das quais as predominantes foram a IB-9 e IB-41 e verificaram ainda que os isolados da raça IB-9 exibiram padrão similar de virulência. No Mato Grosso, Cassetari Neto (1996) identificou em 11 isolados de $P$. grisea a presença das raças do grupo IB (IB-41, IB-61, IB-62).

Esses resultados mostraram que se a variabilidade detectada reflete, de fato, a diversidade do patógeno presente em plantios comerciais há possibilidade de que o patógeno possa se adaptar rapidamente ás cultivares de arroz atualmente em cultivo no estado. É importante ressaltar que esta diversidade pode ter sido desenvolvida em resposta á diversidade existente na população hospedeira amostrada (multilinhas, cultivares compostas, além de quatro cultivares utilizadas como testemunha). Há interesse das instituições responsáveis pela pesquisa com a cultura do arroz no Tocantins em seguir essa linha de pesquisa, com amostragem a ser realizada em plantios comerciais, para se estabelecer uma relação mais estreita entre a frequência de raças e de genes de virulência presentes na população do patógeno e os genes de resistência presentes em cultivares atualmente em cultivo. Conhecer as raças que ocorram em uma determinada região é de grande importância sob o ponto de vista prático, permitindo desenvolver um programa mais eficaz de melhoramento visando resistência às raças presentes e as predominantes nos diversos municípios.

\section{AGRADECIMENTOS}

A EMBRAPA Arroz e Feijão, pela concessão da bolsa de Mestrado à primeira autora.

\section{REFERÊNCIAS BIBLIOGRÁFICAS}

Atkins JG, Robert AL, Adair CR, Goto K, Kozaka T, Yanagita R, Yamada M, Matsumoto S (1967) An international set of rice varieties for differentiating races of Pyricularia oryzae. Phytopathology 57:297-301.
Bedendo IP, Ribeiro AS, Cardoso CON (1979) Variabilidade do fungo Pyricularia oryzae cav. agente da brusone no arroz. Summa Phytopathologica 5:106-109.

Cassetari-Neto D (1996) Brusone (Pyricularia grisea Sacc) em arroz de sequeiro no estado de Mato Grosso: I-Identificação de raças fisiológicas, II-Influência do nitrogênio, fósforo e potássio na infecção do patógeno. Tese de Doutorado. Lavras MG. Universidade Federal de Lavras.

Cornelio VMO, Soares AA, Bueno-Filho JSS, Soares PC (2003) Identificação de raças fisiológicas de Pyricularia grisea em arroz no Estado de Minas Gerais. Ciência e Agrotecnologia 27:10161022.

Filippi MC, Prabhu AS (2001) Phenotypic virulence analysis of Pyricularia grisea isolates from Brazilian upland rice cultivars. Pesquisa Agropecuária Brasileira 36:27-35.

Filippi MC, Prabhu AS, Levy M (1999) Differential Compatibility of Pyricularia grisea isolates with some Brazilian irrigated rice cultivars. Fitopatologia Brasileira 24:447-450.

Leung H, Borromeo ES, Bernardo MA, Nottenghen JL (1988) Genetic analysis of virulence in the rice blast fungus Magnaporthe grisea. Phytopathology 78:1227-1233.

Ling KC, Ou SH (1969) Standartization of the international race numbers of Pyricularia oryzae. Phytopatology 59:339-342.

Prabhu AS, Filippi MC, Araujo LG (2002a) Pathotype diversity of Pyricularia grisea from improved upland rice cultivars in experimental plots. Fitopatologia Brasileira 27:468-473.

Prabhu AS, Filippi MC, Araujo LG, Faria JC (2002b) Genetic and phenotypic characterization of isolates of Pyricularia grisea from the rice cultivars Epagri 108 and 109 in the State of Tocantins. Fitopatologia Brasileira 27:566-573.

Prabhu AS, Filippi MC (2006) Brusone em arroz: controle genético, progresso e perspectivas. Santo Antônio de Goiás GO. Embrapa Arroz e Feijão.

Rangel PHN, Soares DM, Morais OP, Cutrim VA, Diniz JA, Fonseca JR (2006) BRS Alvorada and BRSGO Guará - Irrigated Rice Cultivars for the States Goiás and Tocantins. Crop Breeding and Applied Biotechnology 6:319-322.

Santos GR, Korndörfer GH, Prabhu AS (2003) Eficiência do silício combinado com nitrogênio e tratamento de sementes no controle de doenças do arroz irrigado por inundação. Bioscience Journal 19:43-49.

SEAGRO TO. Secretaria da Agricultura do Estado do Tocantins (2008) Mapa do Arroz no Tocantins, Safra 2007/2008. www. seagro.to.gov.br.

Silva GB, Prabhu AS, Filippi MCC, Trindade MG, Araújo LG, Zambolim L (2009) Genetic and phenotypic diversity of Magnaporthe oryzae from leaves and panicles of rice in commercial fields in the State of Goiás, Brazil. Tropical Plant Pathology 34:77-86. 